Future Anxiety قلق المستقبل

$$
\text { إعداد }
$$

أ أسماء السيد قبيصى أبوزيلـ

باحثة ماجستير / قسم الصحة النفسية

$$
\text { كلية التزبية بقنا - جامعة جنوب الوادى }
$$


قلق المستقبل Future Anxiety

أل أسماء السيد قبيصى أبو زيد

\title{
قلق المستقبل Future Anxiety
}

إعداد

\author{
أ أسماء السيد قبيصى أبوزيل \\ باحثة ماجستير / قسم الصحة النفسية \\ كلية التربية بقنا ـ جامعة جنوب الوادى
}

المستخلص :

قد تناولت الباحثة في هذه الدراسة أهمية قلق المستقبل وتعريفه وأصل كلمة

قلق المستقبل في اللغة وعند علماء المسلمين وعند علماء النفس كما تناولت أنواع قلق المستقبل والنظريات التي فسرت قلق المستقبل ومنها المدرسة السلوكية كما تتاولت سمات ذوي قلق المستقبل وعلاجه وكيفية قياسه. ومما سبق وبعد الاطلاع على هذا الكم من المقاييس قامت الباحثة بإعداد مقياس لقلق المستقبل بأبعاده (الار اسية - المهنية - الاقتصادية - الاجتماعية) الخاص بالدر اسة الحالية ومتغير اتها

حتى يمكن الثعرف على ذوي قلق المستفبل وعلاقته ببعض المنغيرات النفسبة: (مفهوم الذات - مسنوى الطموح - الدافعية للإنجاز) بأبعادهم والمتغيرات الاجثماعية: - (الثو افق الاجنماعي - المساندة الاجتماعية) لدى طلاب الجامعة السنة

النهائية.

الكلمات المفتاحية : قلق المستقبل . 
Future Anxiety قلث المستقبل

أم أسماء السيد قبيصى أبو زيد

Future Anxiety

\author{
Prepare \\ Assma Elsayed Qebasy Abo Zaid \\ Master Researcher / Department of Mental Health \\ Faculty of Education in Qena - South Valley University
}

\begin{abstract}
:
The Researcher has in this study discussed the significance and definition of Future Anxiety, and the origin of the term " future anxiety) in the Arabic language, and among Muslim scientists and psychologists. She has also discussed the types of Future Anxiety and the theories that explained Future Anxiety; e.g., behavioral theory. Moreover, she has discussed the traits of patients with Future Anxiety, the measurement and the treatment.

From the above, and after reviewing that number of scales, the Researcher has developed a scale for Future Anxiety with its dimensions (Academic, Occupational, Economic, and Social) concerning this study and its variables. This enables us to discover patients with Future Anxiety, and to evaluate its relation to the psychological variables (Self-Concept, Aspiration Level, and Achievement Motivation with their dim.
\end{abstract}

Keywords: Future Anxiety. 
لاشك أن القلق بعتبر ظاهرة العصر الحالي لذا ثبوأ القلق مكانا بارزا في الثراث الإنساني الماضي والحاضر و المستقبل ولعل من اهم الدلائل على ثلاك المكانة بحث القلق و الاهنمام به في ضوء علوم وتخصصات عده أبرزها علم النفس و الطب النفسي وما يثصل بهما من تخصصات تتاولت جوانب محدده في القلق لذا فان الفرد يعيش في عصر بطلق عليه عصر القلق والتي قد يلعب القلق فيها دورا رئيسيا لذا كان من الطبيعي أن بنال القلق هذا الاهنمام عبر العصور وفي كافة المجثمات وان يستأثز بنصيب الأسد من جهد الباحثين في مختلف مجالات العلم والمعرفة (خلف

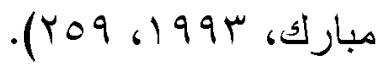

لذا بعد قلق المستقبل واحد من أهم وأكثر الاضطر ابات النفسية التي تبعث على الثُعور بالبأس والهم والعجز و الخوف و التثاؤم من المسثقبل وبالثالي يعيق تحقيق الأهداف لاى من بعانيمن اضطراب قلق المسثقبل ومحاولة التخفيف من حدثه امر في غاية|لأهمبة لما لله من أثنار سيئة على من بعاني منه ويمثل قلق المستثبل خبره انفعاليه غير ساره والثُعور بالثوتز عند الاستغراق في التفكير في المستقبل وشعوره

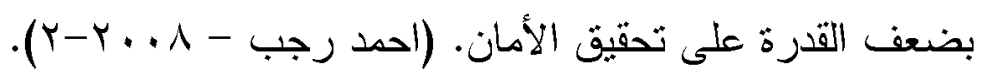

وبما أن الإنسان مخلوق اجنماعيأعطى القدرة على التعامل مع الظروف المختلفة والاستجابة لمستجدات الحياة وما تحفل به من متغيرات اجتماعبه وطبيعية وتسمى مثل هذه الاستجابات والثعامل مع الظروف المختلفة عملية التكيف الاجتماعي وأكبر عمليات التوافق الاجتماعي نظهر تأثثرها على الفرد عندما ينتقل من بيئة نقافيه واجتماعبه إلى بيئة أخرى وذللك لان اختلاف الييئات يؤدى إلى الى اختلاف العادات و التقالبا والقيم فهي أساس بناء العلاقات الاجنماعبة التي ينبغي

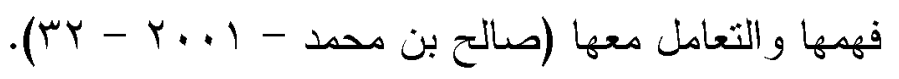


وبما أن طلاب الجامعة فيهم يتجسد المستقبل ويتضح لديهم أفاق المستقبل و استجابتهم للمنغيرات المحيطة اكثر من الفئات الأخرى مما ينعكس سلبا على أدائهج الاكاديمي وأن الضغوط الاجثماعبة تؤثر على إدراك الفرد الثي قد تثئش

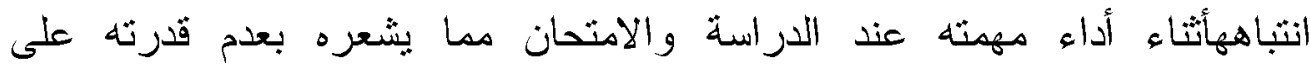
التزكيز(على حسين مظلوم- V. . . I-1) وأن طلاب الجامعة هم المستقبل الذين يتحملون مسئولية تقدم بلادهم وازدهارها وهم يفكرون بشكل كبير في المستقبل

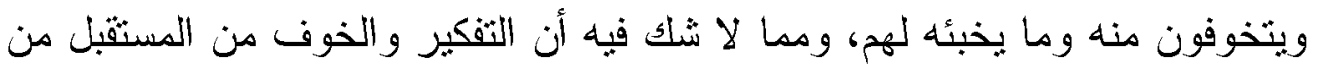

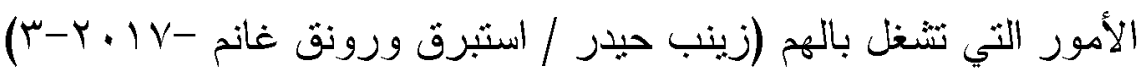

ويعد الإنسان محور هام من محاور اهتمام الباحثين في مجال الصحة النفسية وعلم النفس بثكل عام بهدف التعرث عليه بصورة ثسمح بدراسته بالثكل الذي بعتمد على الرقى للوصول به إلى أقصى درجات الثقدم والنجاح والعمل على بلى مساعدته على تجنب كل ما يؤثر عليه و على أدائه في مختلف مجالات الحياة. (فتحيه فرج - ( وفي ضوء ذلك تحاول الباحثة إلى دراسة ما بعثرى طلاب الجامعة من مشاعر قلق للمستقبل وعلاقته ببعض المتغيرات النفسية ومنها " مفهوم الذات مسنوى الطموح - الدافعية للإنجاز " و المنغيرات الاجنماعية ومنها:" الثوافق الاجنماعي - المساندة الاجنماعية - المتغيرات الديموجر افية " الثي من شأنها أن أن تؤثر على سلوك الفرد من الجنس (ذكر - أنتى) و هذه المتغيرات تؤثر على انفعالات الفرد وسلوكه ونزتبط بالظاهرة محل الدراسة وهو قلق المستقبل " فإن نوقع الفرد لقدراته و إمكانياته المعرفية وسلوكه لمحاولة السبطرة على البيئة و التكيف معها بما

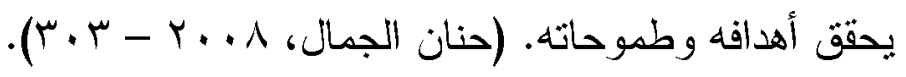
تثضح أهية الدراسة والحاجة إليها من حيث أنها نتخاول بالثحليل و القياس لمتغيرات هامة وهي: (قلق المستقبل ومفهوم الذات ومستوي الطموح والدافعية للإنجازو التواقق الاجتماعي والمساندة الاجتماعية) وتشمل طلاب الجامعة وهم في 
أهم دراحل نمو وتكوين الثخصية واستقلاليتها مدا قد يكون مفيد للقرد في تكوين شخصية مستقلة و العمل على تطوير ها و التخطبط للمستثبل. أصل كلمة القلق: فألفاظ اللغة العربية هي بمثابة درجع للخبرة الإنسانية، فتساؤلنا عن أصل كلمة قلق ومعناها في اللغة العربية، لم ترد هذه الكلمة في هي هي

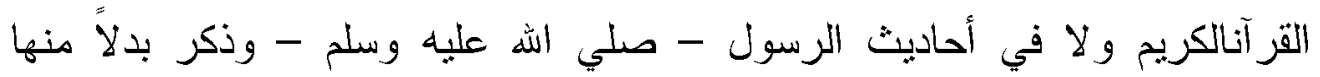

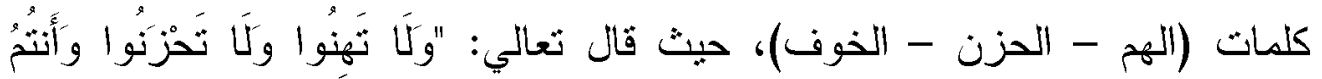

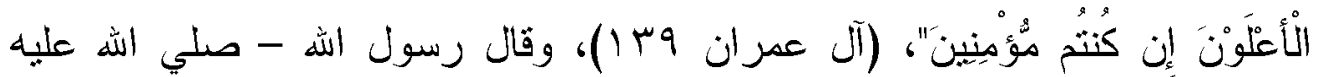
وسلم: "اللهم إني أعوذ بك من الهم..."، ووردت الكلمة في المعاجم العربية بمعاني كثيرة (الانزعاج - الاضطر اب - الأرق - الهم وعدم الاستقرار) و ورد في المعجم

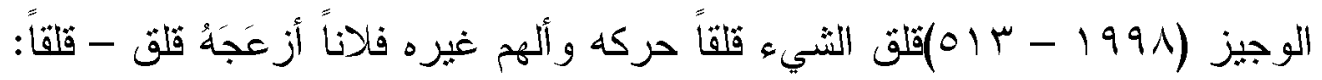

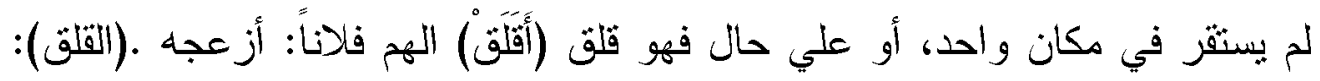
حالة انفعالية ثثميز بالخوف مما قد بحدث ورد في المعجم الوسبط قلث الثيء قلقاً حركه فلم بستقر مكانه واضطرب وانزعج ورد في مجمع اللغة العربية: استخدام

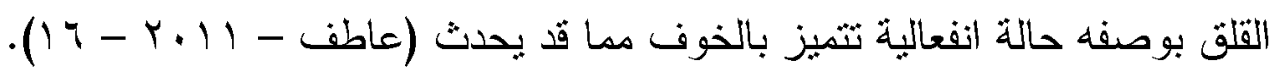
القلق عند علماء المسلمين: حيث لوحظ اهتمام علماء المسلمين بالكتابة عن

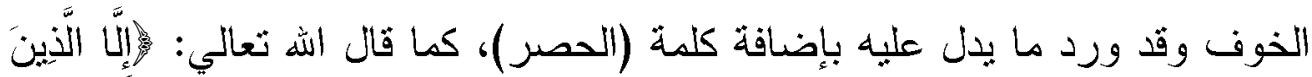

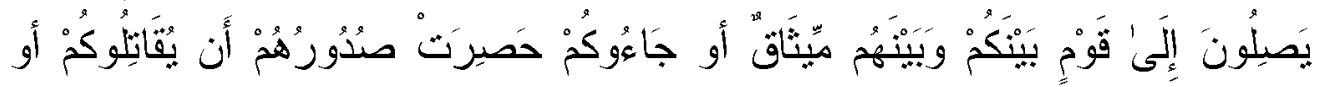

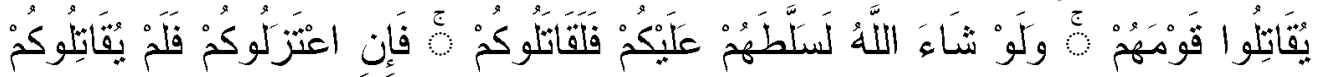

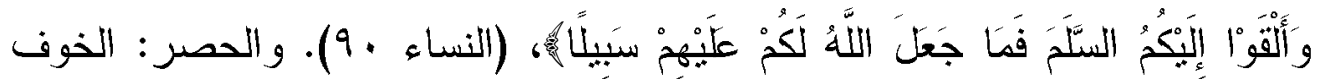
والإحساس المألوف بالقلق، وهو فوق ذلك انغمار نتبجة الإثارة، أو هو حالة من ون الهول في بعض الأحبان إثارة إنذار حنى أن الحصر أفظع ما ثرزح النفوس تحت هـ وطأته من إعباء، والحصر إما و اقعي أو عصابي أو أخلافي نتيجة خطر داخلي فهو إنها

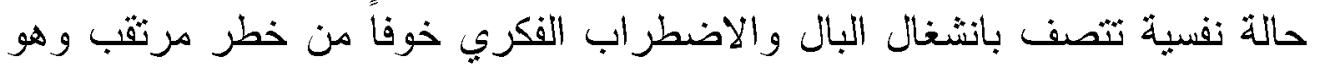

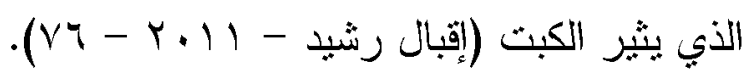


ويذكر البقاعي بهrهـ أن اله سبحانه وتعالي جعل لكل عضو هن أعضاء

الإنسان كمالا، إن لم يحصل عليه كان في قلق وانزعاج واضطراب فكمال العين الإبصار، والأذن السمع، واللسان النطق، وجعل كمال القلب نعيمه وهدئه ولذته

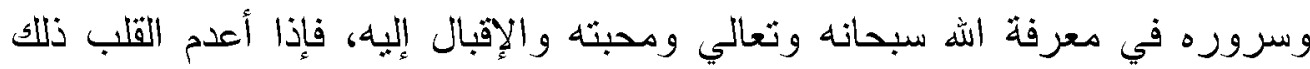
كله كان أثند عذاباً من الذي فقد النور الباصر ولا سبيل إلى الطمأنينة إلا بتحقيق

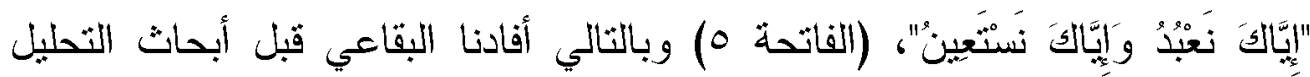
النفسي أن القلق بعمل كإنشارة نتبيه ورد فعل لأبي خطر بلاحق الإنسان. (فوزي -

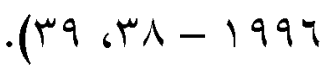

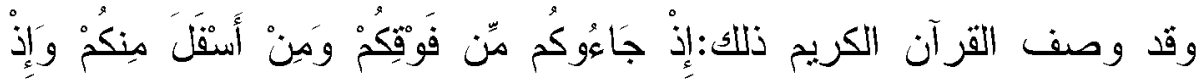

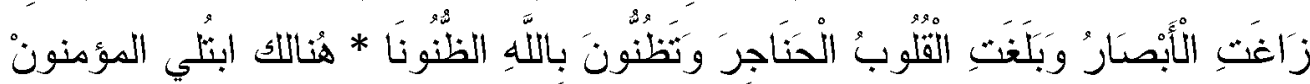

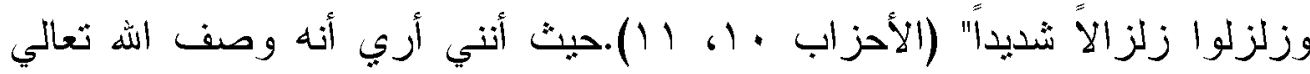
الخون النتديد الأبي يعنزي الإنسان ويلاحقه من فوقه ومن أسفله فيكون محله القلب

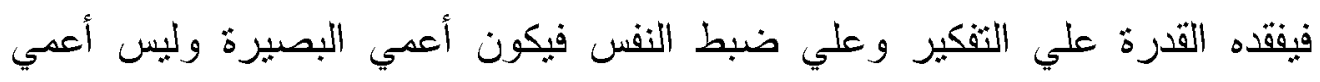

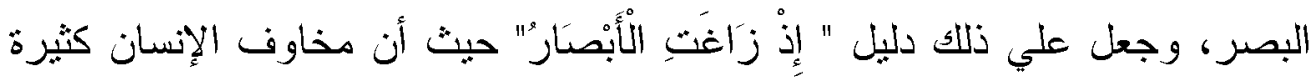
خوف "مادي واجثماعي وديني"، ولذا فإن هدف الإنسان التخفيف من حالة الثونر و القلق والثعور بالأمن والأمان و الطمائنينة والخوف هام ويؤدي وظيفة هامة في حياة

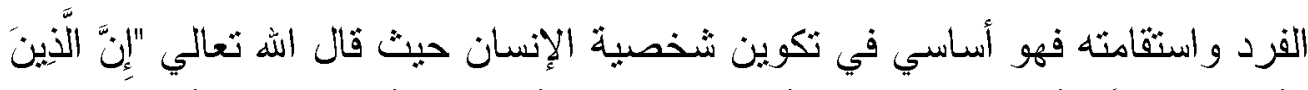

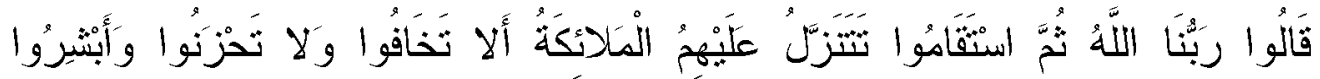

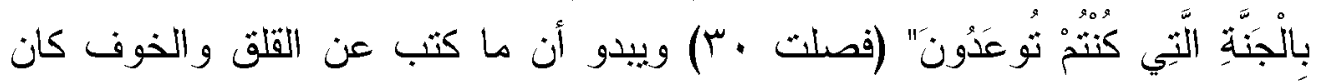
قليلاً في العصور الإسلامية حيث لوحظ اهثمام العلماء المسلمين بالكتابة عن الخوف من اله وعذابه والموث، وقد سبث الإمام الغزالي علماء النفس في تعريف القلق و التمييز بين القلق الموضوعي والقلق العصابي فقد عرف الإمام الغزالي القلق بأنه تألم القلب واحتر اقه بسبب نوقع مكروه في المسثقبل، وقسم القلق إلى قسمين: - 
قلث عادي ويشنمل علي: - الخوف هن الأشباء الموضوعبة كالحريث و اللصوص والحبوانات المفترسة... الخ، ويعثبر هذا صفة حمبدة لصالح حياته

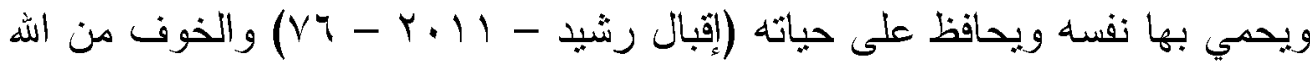
مقرون بالرجاء والطهع في رحمته وهو صفه حمبدة لأنه بدفع الفرد لصالح الأعمال و الثقوى في الدنيا لينعم بالسعادة في الدنيا والأخرة (فوزي قابيل - بو 199 - 1؛).

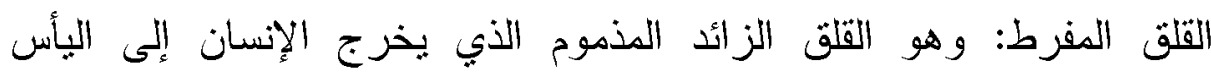
و القنوط ويمنعه من العمل ويسبب له الأمر اض والضعف وزوال العقل (إقبال رشيد

$$
\cdot(V T-r+1)-
$$

وأحياناً يؤدي إلى الموت، وقد حث الرسول - صلي الله عليه وسلم - علي

التحلي بالخوف من الله والرجاء فيه، وقال: "أنا أخوفكم الله، ونهي عن الخوف المفرط والهم، وقال: "اللهج إني أعوذ بك من الهج "ويقول الإمام الغزالي: "الخوف سوط الله يسوق به عباده إلى المواظبة علي العلم و العمل لينالوا به مرثبة القرب من الله تعالي، فالخوف له قصور وله إفراط وله اعثدال و المحمود وهو الاعتدال ويعثبر علي بن حزم أول من ألف كتاباً عن القلق، ويشير ابن حزم إلى أن الهم هو خبرة

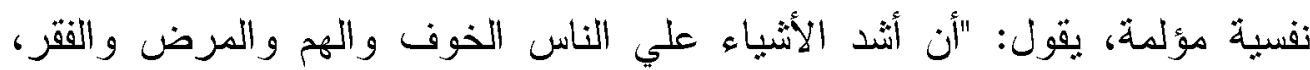

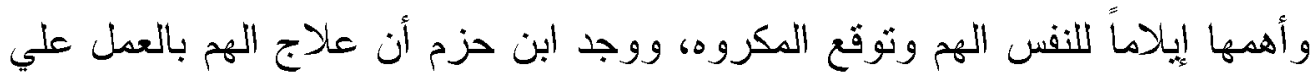

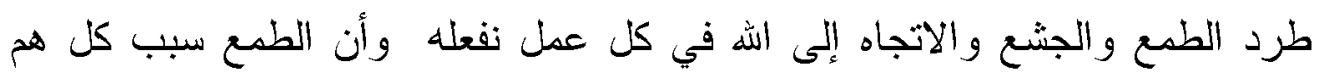

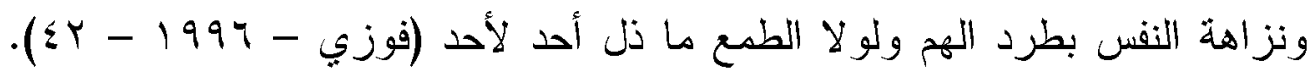
ولذا تزي الباحثة أن القلق هو الذي يحث علي العدل وبه يتم إنهاء المهام المطلوبة

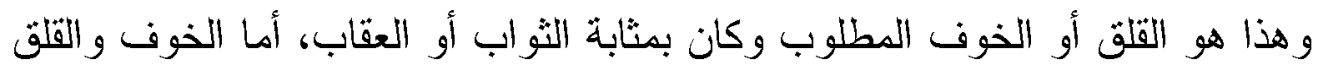
المفرط الزائد المزموم كالضرب الذي يؤدي إلى الموت أو مثل من أخذ الدواء يثنفي به هذا هو المحمود أما الأخر فأخذ الجرعة زائدة أدت إلى الموت و إلي انهيار حياته

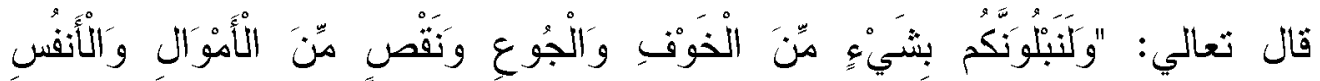

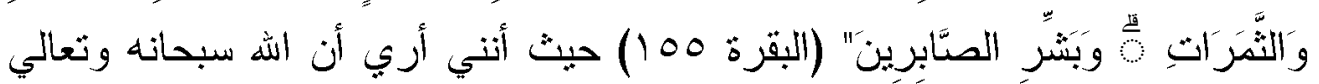


وضح في هذه الآية (المرض ونوعه وعلاجه)، وهو الابتلاء من اله سبحانه ونوعه

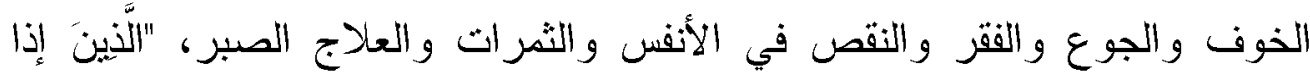

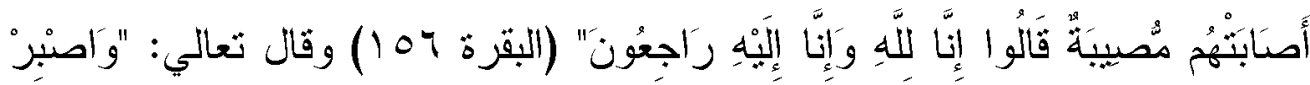

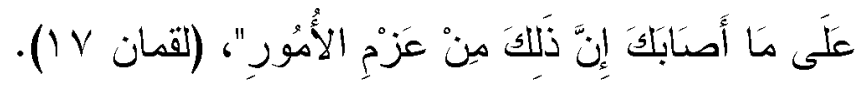

\section{تمريف قاق المستقبل :}

عرفه أبو مدين الثافعي 190V هو الخوف من المستقبل ويتمبز بالرغبة في التخلص

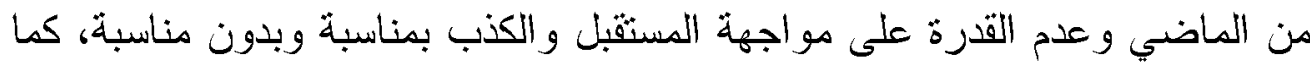
أنه يتميز بالرجوع إلى مرحلة سابقة من مراحل النمو، وتظهر عليه علامات التتاؤم

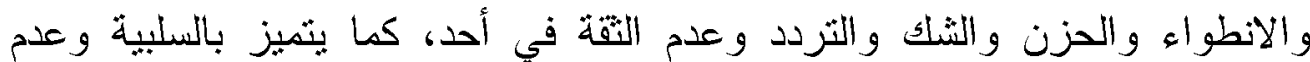

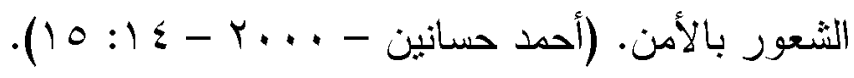

كما يعرفه سيجموند فرويد سرو (بأنه حالة من الخوف الغامض الثدبد الذي

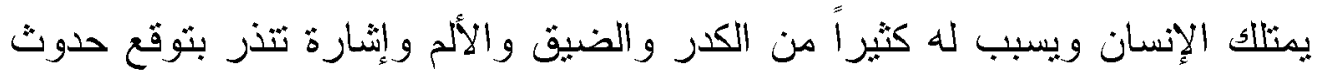

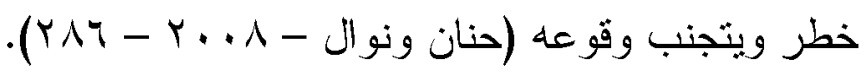

كما يعرف أحمد حسانين ( ... - ـ . . بأنه حالة من التوتز والقلق وعدم الاطمئنان والخوف من التغير ات الغير مرغوبة في المستقبل في الحالة القصوى لقلق المستقبل فإنه قد يكون ثهديداً بأن هناك شيء ما غير حقيقي سوف يحدث للشخص.

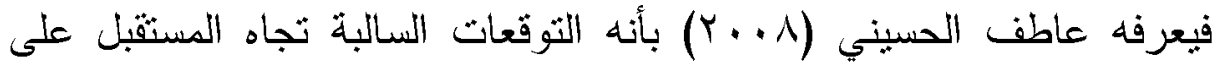
المستوى الثخصي والمحلى والعالميهو خوف أو مزيج من البأس والأمل بالنسبة للمسثقبل والأفكار الوسواسية وقلق الموت و اليأس بصورة غير مقبولة.

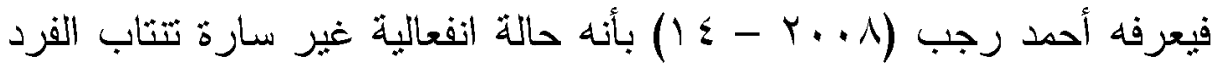
أثتاء التفكير في المستقبل ويتوقع خلالها تهديداً لمستقبله وما سوف يكون عليه في المسنقبل والخوف و العجز من مشكلات اجتماعيةو اقتصادية مصحوبة بشيء من عدم الثركيز والتفكير الغير صحيح مع أعر اض جسمية وضعف عام. 


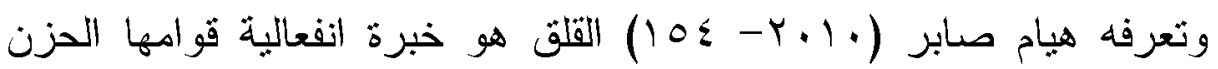
و التوثز و الكدر والثعور بانعدام الأمن وما يصاحب ذلك من أعر اض معرفية، مثل:

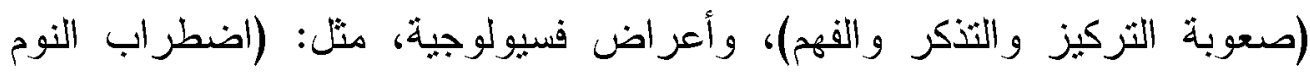

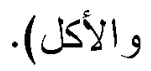

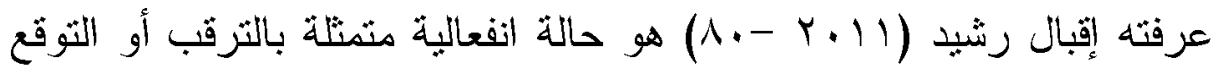
مصحوبة بعدم الاطمئنان لما تحمله الأيام القادمة، تدفع الفراد إلى التفكير في مستقبل حياته وما سيحدث له من أمور غير مثوقعة للفرد نكون مبعث ألم للفرد.

ويشر عاطف الحسيني (11 (Y - Y Y): قلق المستقبل بأنه خبرة انفعالية غير سارة يمثلك الفرد خلالها خوف غامض نحو ما بحمله الغد والتنبؤ السلبي للأحداث المنوقعة والثعور بالانزعاج والتوثز والضيق عند الاسنغراق في التفكير نحو المستقبل، وهو القلق الذي بحدث بسبب التفكير أو التصرث أو السلوك أو النشاط تجاه المستقبل.

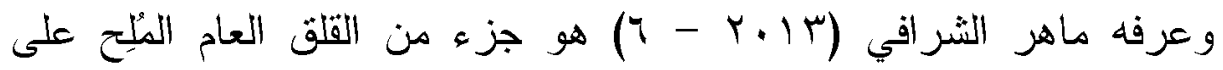

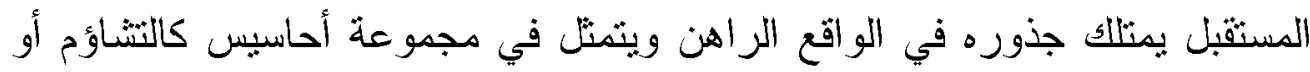
إدراك العجز في تحقيق الأهداف العامة وفقدان السيطرة على الحاضر وعدم التأكد

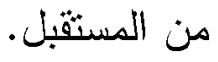

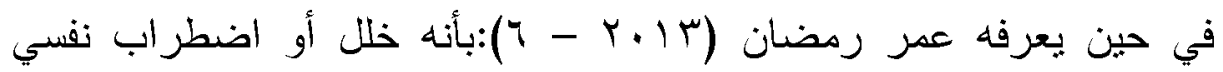

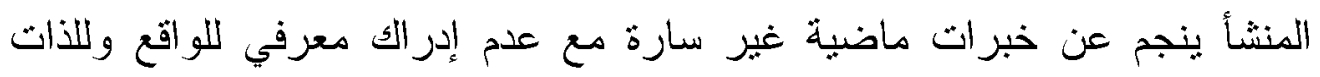
خلال استحضار الذكريات الماضبة مما قد بدفعه إلى تذمير الذات و العجز الواضح وتعميم الفتل ويؤدي به إلى حالة من التشاؤم من المستقبل وقلق التفكير في المستقبل والخوف من مشكلات الاجنماعية والاقتصادية المستقبلية المثوقعة وقد حظي مفهوم التوقعات المستثبلية علي اهنمام الباحثين بالدوافع الإنسانية والسلوك الإنساني هذا وقد اهتمت بعض البحوث بدراسة القلق في ضوء المستثبل وعليه فان قلق المستقبل 


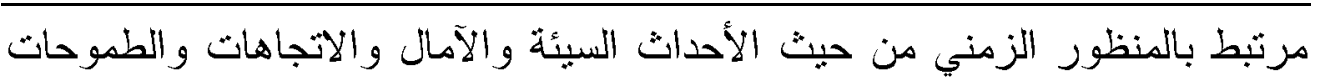
وبذلك يعد قلق المستقبل مزيجاً من وعي الفرد بالتوقعات المستقبلية وقدرثه علي مواجهنها. بوجه عام بعد قلق المستقبل مقياساً لقدرة الفرد على ثعريف المستقبل ورؤيته، تم تتاون هذا المفهوم تحت دسميات مختلفة منها: التوجه نحو المستقبل رؤية المسثقبل - اتجاهات المسثقبل - إدراك الفرص المسثقبلية - التفاؤل بشأن المستفبل والمستقبل له ثأثثير عميق على الدافعية والسلوك الإنساني، فمعظم الدوافع الإنسانية نكون موجهة نحو المسنقبل وتكيفه النفسي وأهدافه وطموحاته في ضوء

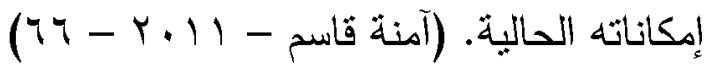

حيث أن كل أنواع القلق لها بعد مستقبلي وهذا المستقبل محدود للغاية بمساحة زمانية، ومن خلال التعريفات السابقة فإن قلق المسثقبل: هو التوقعات السليية من (ظن وثرقب) للأحداث المستقبلية على المستوي الثخصي في فترة طويلة من زمن

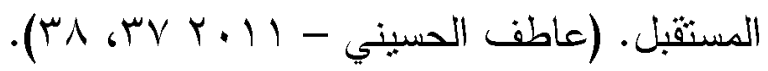

ويذكر حالة القلق الوقتية مرثبطة بالموقف فإذا كان هذا الثخص يعيش حالة

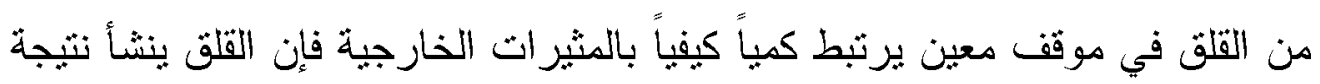
تلك المثيرات الخارجية منعلقة بموقف ويرثبط بالاستعداد الخاص بالفرد للقلق مع

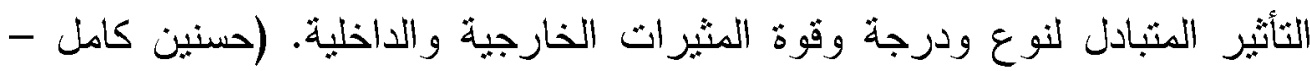
$.(1): 1 \cdot-19 \wedge \varepsilon$

يثير سبيلبرجر إلى الاختلافات الفردية الثابنة نسيياً في قابلية الإصابة بالقلق الني نزجع إلى الاختلافات الموجودة في الأفراد في استعدادهم للاستجابة للمواقف المدركة كمو اقف تهديدية بارتفاع حالة القلق وكمفهوم سيكولوجي فإن سمة القلق لها

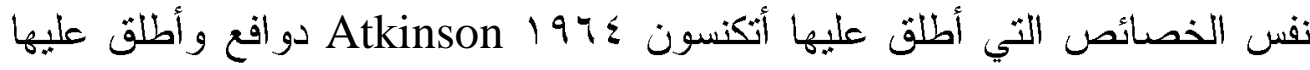

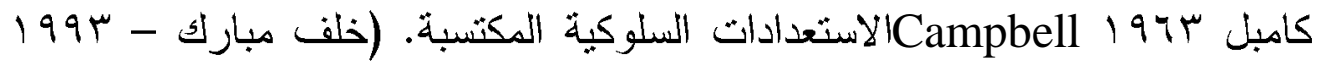


ويذكر أن النخص الذي لديه نزوع قوي ناحية الثُعور بالقلق لا علاقة له بالمثيرات التي سببت حالة القلق تلك ويوصف بأنه لديه سمة دائمة للثخصبة.

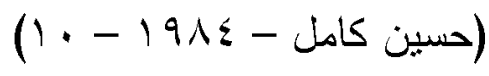

لذا فالقلق شرط أساسي للصحة النفسية لأنه مؤشر بدل على النوثز الذي

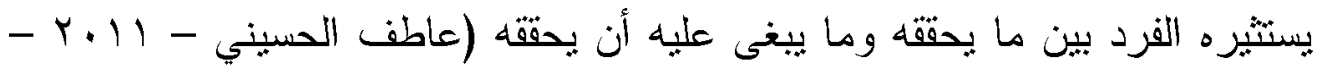

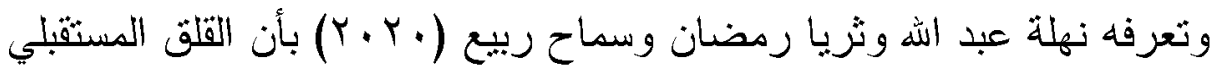
هو حالة من عدم الترتيب والإحباط وعدم اليقين والخوف والقلق من تغيرات غير مواثية في مستقبله الثخصي البعبد وسيكون هذا ثهديدًا وذعرًا من شيء حقا قد

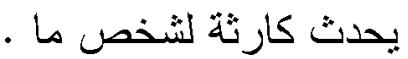

وقد عرفت الباحثة "قلث المستقبل بأنه حالة انفعالية من الخوف وعدم الاطمئنان عند التفكير في مستقبله (الدراسي - المهني - الاجتماعي - الاقتصادي) وما سوف يعتريه في مستقبله حنى بستطيع نحقيق ما يريد من أهداف وطموحات إلا أن فشله في تحقيق ذلك بضعه في دائرة قلق المستقبل. أما التعريف الإجرائي هي الدرجة التي بحصل عليها المستجيب من طلاب الجامعة على ققرات المقياس لقلق المسنقبل بأبعاده "الار اسية - المهنية - الاجثماعبة

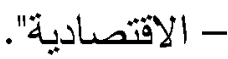

\section{النظريات التي فسرت قلث المستقبل:}

القلق في نظرية المدرسة السلوكية كان موضوع تغبر السلوك هو الأساس

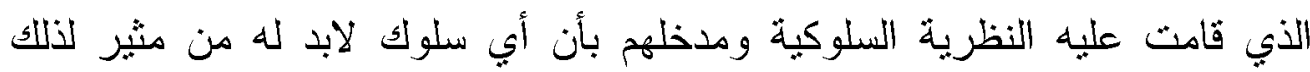

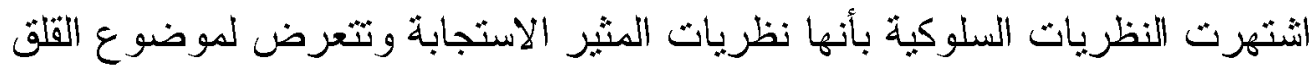


هن حيث علاقته بعملية التعلم وأثزه عليها (فوزي قابيل 1994 - سب) ويركز السلوكيون على عملية التعلم وثؤكد بأن الأنسان بتعلم القلق والخوف ويتعلم السلوك بك

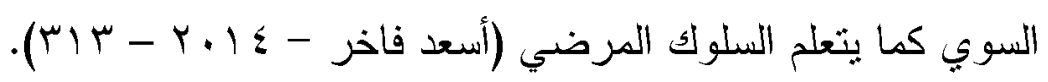

لذا بعثقد أصحاب النظرية السلوكية أن معظم أنواع القلق ناشئة عن الاشتراط

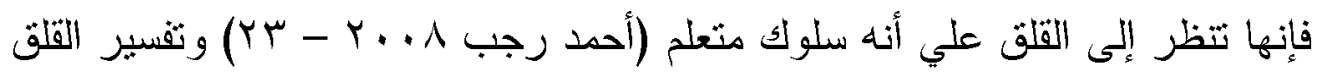
في ضوء الاشتر اطو هو ارثباط مثير جديد بالمثير الأصلي حبث بصبح المثير الجديد

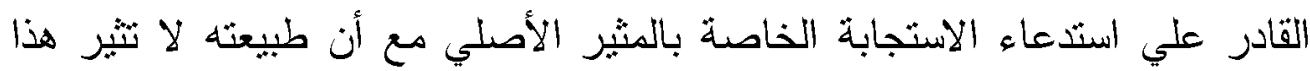

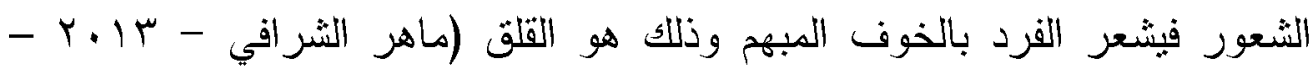
اس) فهو استجابةاتنتراطية لمثير لا بدعوا للخوف أو القلق ولكن تكرار هذه ودئ الاستجابة يؤدي إلى تأكيدها وذلك حسب الاستعداد الثخصي للفرد (استثرق

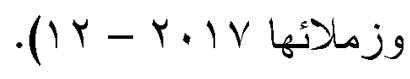

فالمدرسة السلوكية لا ثعثرف بالعمليات اللثتعورية ومن ثم تكون الصر اعات المولدة للقلق صراعات شعورية بين رغبة ورهبة وتعمل على التخلص منه عن طريث المحاولة والخطأ حثى يقع على سلوك يخفض التونز ومن ثم يلقي التعزيز ويثبت في صورة نعلم والصحة النفسية عند المدرسة السلوكية هي نتاج لعملية التعلم والتشئئة الاجنماعية التي بثعرض لها الفرد منمثلة فيما بتعرض له من مواقف

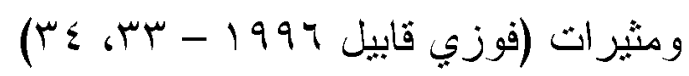

القلق في نظرية (مورر Mowrer) بدأ مورر مناقشته لظاهرة القلق حيث وضع اهنماما كبير الطبيعة العلاقة بين الطفل وو الديه في عملية التطبع الاجنماعي وأثز الدفء العاطفي حيث يستطيع الفرد العصابي أن يمتص كثير المن المطالب التي ثفرضها عليه عملية الثطبيع الاجنماعي أي أن الثخص العصابي في رأي مورر يسلك عادة سلوك غير مقبول اجنماعيا وهو يسعي بذلك إلى إثباع رغباته ونزواته

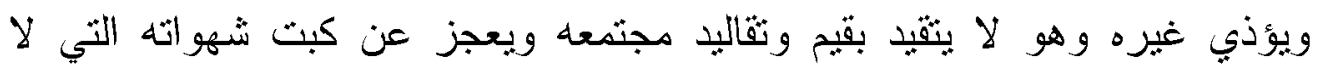

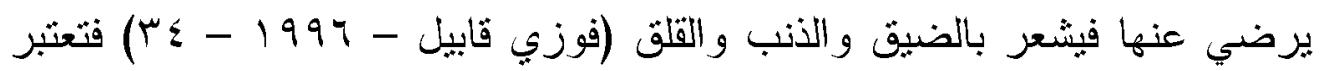


القلق استجابة داخلية تحرك سلوك الفرد في المواقف التي لا برغبها وهو بذلك بينشأ عن صر اعات شعوريه تشسم بالإقدام والأحجام مما بنتج عنه إصابة الفرد بالثونز و القلق وينظر للقلق علي أنه سلوك متعلم يتعلمه الفرد وفقا لمبادئ التعلم الأساسية لذلك يعرف(مورر)القلق علي أنه رد فعل شرطي لمثير مؤلم (داخلي أو خارجي) يصاحبه ثونر ينتج عنه تتبيه أجهزة الجسم لبستجيب الفرد بطريقة تشاعده علي رئي

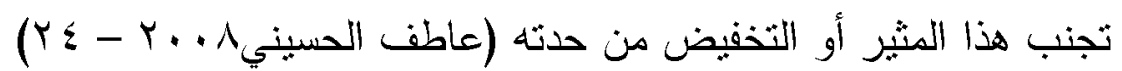
ومن هنا جاءت نسمبة نظرية "مورر " في القلق بنظرية القلق الناتج عن الثعور بالذنب وقد افترض أن إثباع الرغبات التي لا تزضي عنها الأنا الأعلى يثير الشعور بالذنب الذب يؤدي بدوره إلى القلق وأن الخطيئة وقمع الأخلاق هي أساسي إني الاضطر ابات النفسية وقال " إذا ثمسكنا بالأخلاق و القيم وعملنا ما برضي ضوض ضمائرنا

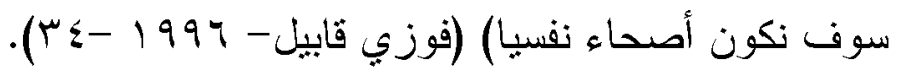

القلق في نظرية (سكنر) skinner ولا تختلف نظرية سكنر كثير أ عن مسار التفسير الاشثراطي الكلاسيكي إذ يري " أن السلوك إجمالا بما في ذلك السلوك غير

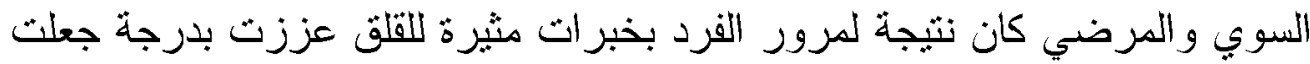

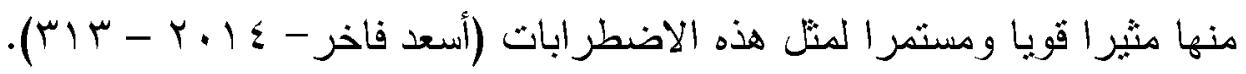
القلث في نظرية واطسون وباقلوف أظهر (واطسون) زعيم المدرسة السلوكية أن عملية الثعلم ثتم عن طريق اقتران المثير الثرطي والمثير الطبيعي ومن ثم رثم يستجيب الفرد لظاهرة الخوف أو القلق ويصبح الخوف من المؤثر الثرطي دافعا مكتسبا وعن طريق النصميم في نعلم القلق والخوف يلاحظ أن المثيرات الثبيه لذلك والأكثر شبها بها هي الأكثر إثارة للقلق والخوف (المرجع السابق) والذي اسنطاع أن يسبب خوفا لدي الطفل " ألبرت " البالغ من العمر أحد عشر شهرا حيث تعود هذا الطفل اللعب مع أحد حيوانات التجارب ثم شرط و اطسون رؤية الطفل لهذا الحيوان بمثير مخيف في أصله وهو سماع صوت عالي ومفاجئ 
وبعد حدوث الاشتز اط أصبح الطفل يخاف من الحيوان الذي كان يصر على رؤيته من قبل وعليه قد أصبح الحيوان في هذه التجربة بمثابة موضوعات محايدة في

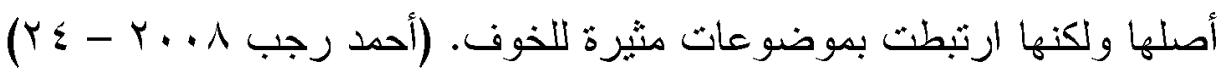

وبذلك يمكن القول إن المؤيدين للنشريط الكلاسيكي برون أن كثير من اضطر اباتتا وسماتتا الثخصبة هي استجاباتاكنسبناها من خلال عملية التشربط ثم تحولت إلى عادة مرضبة وليست نتاجا لغر ائز طبيعية أو صراعات داخلية فالقلق و الخوف و التفاؤل و التشاؤم جمبعها يمكن تفسير ها بالاعتماد على الاشتثر اط على أنها استجابة شرطية لمنبهات اكتسبت قدرثها علىإثارة هذه الجوانب السلوكية بسبب ارتباطها بأحداث تبعثعلى الضرر أو الألم أو النفع أو الفائدة كنتيجة اشتثراطية

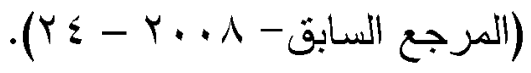

ويري كل من بافلوف وواطسون أن القلق يقوم بدور مزدوج فهو من ناحية

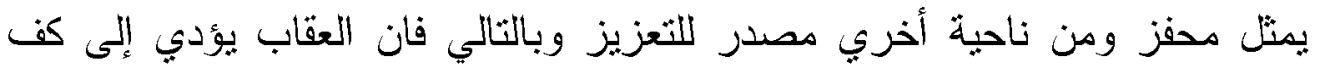
السلوك الغير مرغوب فيه فهو يعد صفة نعزيزية سلبية تؤدب إلى تعديل السلوك

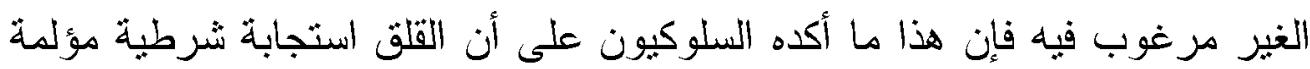
فالسلوكيون ينظرون إلى القلق على أنه سلوك منعلم من البيئة الثي يعيش وسطها

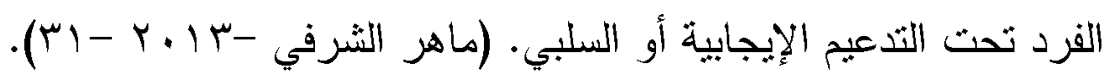

في حين أظهر بافلوف أن الاستجابة الغريزية الواحدة تثير ها حوافز عديدة ولا تقتصر استثارنها إلى الحافز الطييعي المرتبط به في الأصل فاستجابة الكلب بإفراز اللعاب فعل منعكس يحدث عند رؤية الطعام (المثير الطبيعي) ويمكن أن يحدث إذا بها اقترن تقديم الطعام بصوت الجرس ويصبح الجرس مثيرا شرطيا فتبع استجابة إفراز اللعاب بصوت الجرس وذكر أن استجابة الواحدة يمكن إخضاعها لعدد كبير

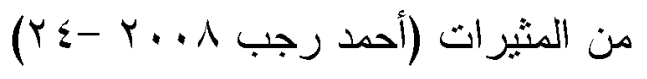


القلق في نظرية وولبي يعرث وولبي القلق على أنه نمط من أنماط الاستجابة و التي هي شكل مميز جانب من استجابة الجانب العضوي للإثنارة المؤدية فالمثرات الثي كانت سابقا عاجزة عن انبعاث القلق بمكن أن نكتسب القدرة علىانبعاثه في الوقت الذي بكون القلق هنبعثا لدية نتيجة لمثرات أخري وتعتبر الأعرض المرنات المرضية هي استجابة تجنب القلق فالقلق و الخوف يمثلان شيئا واحد كل منهها مر ادف للأخر

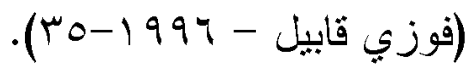

ولذلك يري ولبي أن القلق استجابة القرد لاستشارات المزعجة وأن القلق استجابة خوف يستشار بمثيرات ليس من شانها أن نثير هذه الاستجابة و إنما اكتسبته

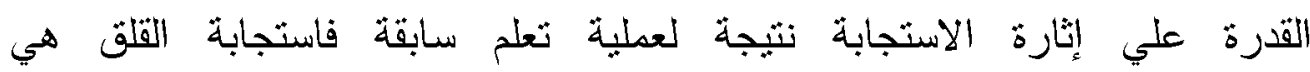

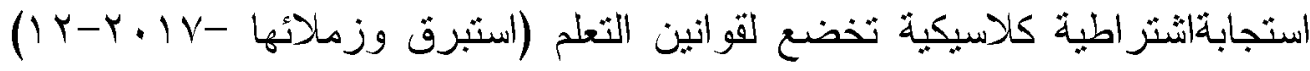
ويري ولبي أن العصاب بنشا عن ارنباط مثناعر القلق كلما ظهر هذا المثير المحايد

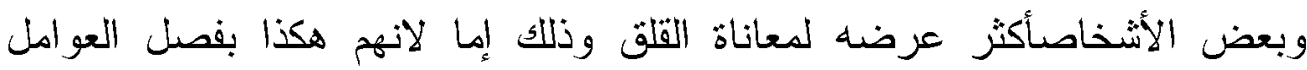
التكونية أو بسب خبرات تعلم سابقة ويري أن المصاب بالقلق العصابي لدية استجابة قلق شرطبة لمثيرات غير محدده بل وقد تكون داخلية (فوزي قابيل - 999 1-هץ) القلق في نظرية باندورا Bandura وقد نطور الفكر السلوكي بظهور نظرية التعلم الاجنماعي لباندورا الذبي أكد على أهمبة التفاعل المثبادل بين المثيرات وخاصة الاجنماعية ومنها السلوك و العوامل الثخصية و العقلية المعرفية والانفعالية الوجدانية وبذلك يري أن ظهور القلق مرثبط بحدوث مثيرات غير مرغوبة فيها فاذا كان لاي الفرد استعداد نفسي لظهوره منمثلا بالمفهوم السلبي للفرد عن قدارثه وعليه فإن القلق وإن عبر عن استجابات لمثيرات خارجية مؤلمة فان هذا الارثباط يبقي

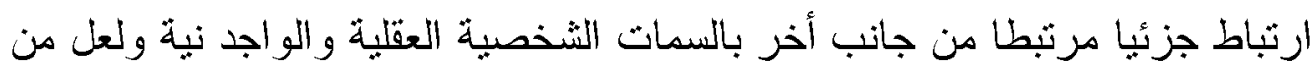

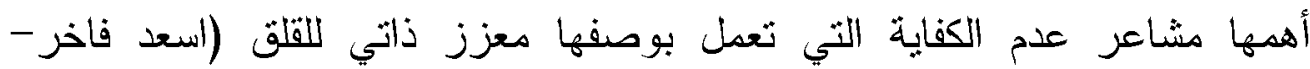

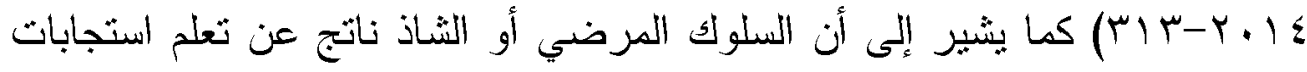
غير تواقفيه وذلك من خلال الملاحظة أبي أن المنطوات الاجثماعي في التعلم يلاحظ 
Future Anxiety لق المستقبل

ألمي أسماء السيدل قبيصى أبو زيد

عند الثعامل مع الأمر اض النفسية - التفاعل بين الخصائص السلوكية وأحداث المثير وهو ما يساعد في تفسير واكتساب واستمرار الاستجابات اللآسوية ويساعد في

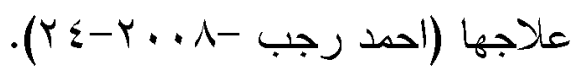

\section{الخلاصة: تطورية الملدراسة السلبوكية}

مورر - حيث أن أثر الدف العاطفي بين الطقل ووالديه له أثر كبير في عملية الثطييع الاجثماعي لذا فان القلق رد فعل شرطي لمثنير داخلي أو خارجي بنتج عنه استجابة.

سكنر - حيث يرجع القلق مرور الفرد بخبرات مثثرة للقلق وعزز هذا المثير ليستدعي استجابة.

وولبي - اعثمدت هذه النظرية على المثير والاستجابة الاتثراطية تخضع لقو انين التعلم في تفسير القلق حيث افترضأن القلق برثبط بالماضي والخبرات السابقة التي سبق وأن تعلمها في حباته.

بالفوف واطسون - يرون أن السلوك بتعلم عن طريق اقتران المثير الثرطي بالمثثر الطييعي ومن ثُ بستجب الفرد للخوف والقلق ويصبح المؤثر الثرطي دافعا مكتسبا عن طريق التعميم في التعلم وأن الاستجابة الغريزية الواحدة ثثير حوافز عديدة لا ثقتصر على الحافز الطبيعي.

باندور ا- أن السلوك يخضع للتعلم الاجنماعي والعوامل الثخصية والاجثماعية و التفاعل المتبادل بين المثير و السلوك.

وبذلك يري أصحاب المدرسة السلوكية أن السلوك مكتسب ولكنها أهملت اللاشعور وركزت علي الظاهر واعتمدت على المثير والاستجابة وفسرت القلق على أنه استجابة اشتر اطية بين مثثر شرطي ومثير طبيعي فهم بعطون العوامل الخارجية دورا كيير في حدوث القلق وتعديل السلوك. 
و اتفقت السلوكية مع التحليلية في أن القلق برثبط بالماضي والخبرات الماضية السابقة التي سبق وأن نعملها في حياته الأولي وثري الباحثة أن قلق المستقبل ينشا حينما يو اجه الفرد الصعاب في نحقيق أهدافه وطموحاته وخاصة إذا كانت طموحاته وله وله

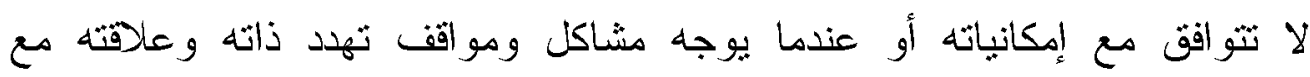
الآخرين وخوفه من الانتقاد كل ذلك يشعره بعدم الأمن والاسنثرار النفسي - أما المدرسة السلوكية فتعد القلق استجابة لخطر معروف ومحدد وأن القلق سلوك مكتسب متعلم عن طريق نعلم خاطئ في السلوك فهو منعلم من البيئة سواء شكل مباشر أو من خلا الاشتراط ومما سبق تستتنج الباحثة أن عمليات التشئئة الاجتماعية (المساندة والتوافق) الأسري والاجنماعي لدي الفرد نؤثر عليه وعلي سلوكه وخاصد

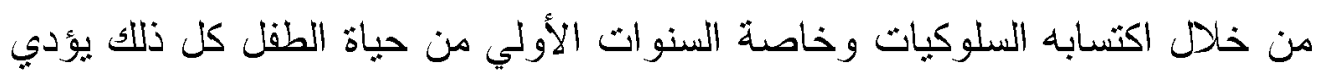
إلى ظهور القلق المسثقبلي لايه وأيضا عمليات التنشئة النفسية لها دور كيير في نمو القلق وخاصة في مرحلة الطفولة والمر اهقة حبث بيؤثر ذلك علي ثقويم الفرد لنفسة وذاته و التقليل من شأن الذات لديه ومستوي طموحة وو اقعتيه ويؤدي ذلك إلى ظهور قلق المستقبل وخاصة في مواقف التقويم وذلك بسبب أن الإنسان دائم التفكير في مستقبله ومسنواه التعليمي والاقتصادي والاجنماعي الأبي ينمني أن يكون عليه

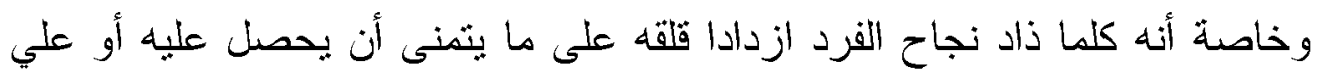
أن يفقد ما حصل عليه وازداد ثركيزه للمحافظة علي ما حصل عليه بل وللحصول

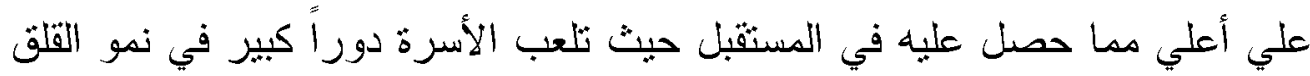
وخاصة في مو اقف الثقويم لدي الفرد سبب اعتمادهم علي الأسرة في إثباع حاجتهر والحصول علي الاستحسان هذا بقلل من ظهور القلق وينمي لديه الاطمئنان و الإحساس بالأمان النفسي.

\section{-سمات ذوى قاق المستقبل: -}

حبث إن هناك مجموعة من السمات الني يثسم بها الأشخاص الذين لديهم قلق مستقبلي من أهمها ما بلىى:- الثركيز على أحداث الوقت الحاضر أو الهروب نحو 
الماضي- الانسحاب من الأشطة البناءة دون المخاطرة - الحفاظ على الطرق الروتينية المعروفة في التعامل مع المواقف الحياه - الانطواء وظهور علامات

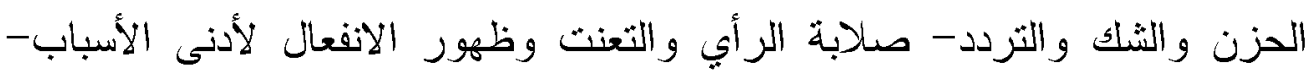
الشعور بالخوف وعدم الراحة الداخلية لترقب حدوث مكروه - تتتت الانتباه وعدم القدرة على التركيز والنسيان وذلك لاختلال أداء التسجيل في الذاكرة مع الثعور بالأرق وعدم القدرة على مواجهة المستقبل - ضعف التقة في قدراته و إمكانياته فلا يمكنه تحقيق ذاته أو يبدع وذلك يشعر بالنقص ويظهر على نفسيته ويظهر في

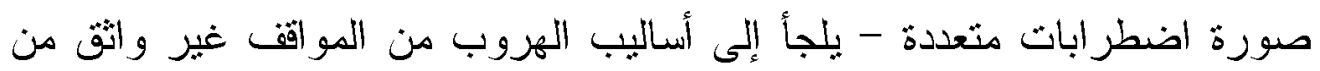
نفسه وقدر اته و إمكانباته وعدم الثقة في الآخرين - الثنعور بعدم الأمن والطمأنينة على الصحة والرزف والأسرة والمستقبل - يكثر من استخدام الحيل الدفاعية فهيأفضل السبل للتعاهل مع الحياه من وجهة نظره -الشعور بالوحدة وعدم القدرة على تحسين مسنوى المعيشة وعدم القدرة على التخطيط للمسثقبل وقلة المرونة والاعتماد على الآخرين في ثأمين المستقبل - إرجاع ما بحدث له من مواقف غير ساره إلى عوامل خارجية هذ يفقده تماسكه المعنوي ويصبح عرضه للانهيار

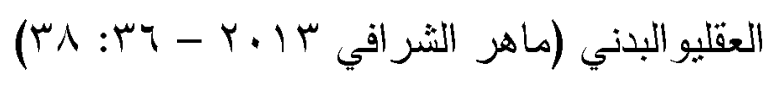

\section{علاج قلق المستقبل: -}

من خلا ما سبق يلاحظ أن قلق المستقبل له العديد من الأثار السليية التي لابد من

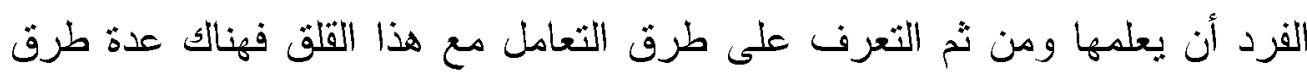

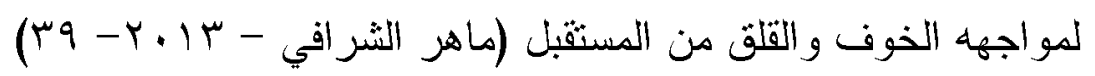

ولذا فإن القلق العصابي من أكثر الأمراض النفسية|ستجابة للعلاج، هذا فإن

الأشكال المنتوعة من القلق والخوف على المسثقبل تتشأ من أفكارنا وتفسيرنا للأحداث في الحياة والتي تصرف في المستوى العقلي، فإذا استطعنا أن نفكر ونئ 
بوضوح وأن نصحح الأشياء في عقولنا فإن مشكلاتتا وقلقنا من المستقبل سيقل

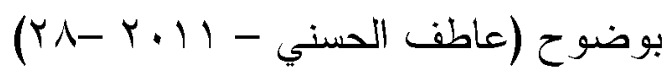

فإن المواقف التي ثثير القلق بأنواعه تشترك فيما بينها بأنها جميعاً تثعلق

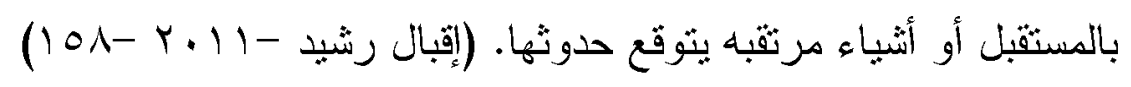

لذلك تعدت طرق العلاج بما يناسب الحالة وينتوع العلاج من نفسي - طبي -

$$
\text { بيئي - سلوكي. }
$$

العلاج النفسي لقق المسثقبل بهدف إلى نطوير شخصية الفرد وزيادة بصبرثه وتحقيق الثوافق القائم على مناقتنه المريض ومحاوله إقناعهم بأفكار منطقيه و اقعبيه للتعامل مع الحاضر و المستقبل وتبصيرهم بمثكلهم ومحاولة حل ثلك المثاكل من خلال العلاج بالمعنى أحد الطرق العلاجية التي يمكن أن بخفض من قلق المستقبل ويستخدم فنيات علاجية تعتمد على المناقتشة الإقناع من خلال تكوين علاقة علاجيه تثميز بالدفء والتفاعل الناجح ومساعدنه على تتميه قدراته بعيدا عن توقعاته في

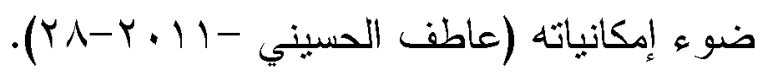

حيث يعد قلق المستقبل واحداً من أهم وأكثر الاضطرابات النفسية التي ثبعث على الشعور بالعجز والخوف من المستفبل مع محاوله التخفيف من حدنه وبذلك فإن كل أنواع القلق المعروفة لها بعد مسنثبلي فهو نوع من أنواع القلق التي تثكل

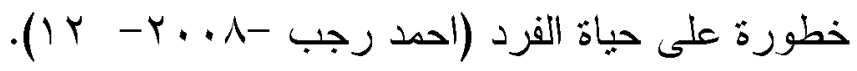

ومن ثم فقد تكون هذه صدمه المستقبل أخطر أمراض الغد فهو مرض لن

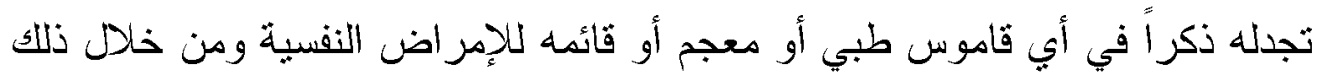

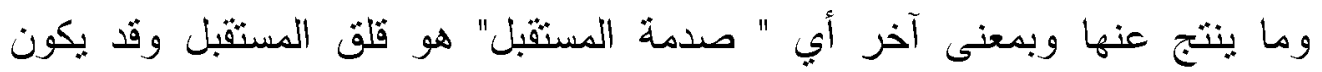
أحدهما جزء من الآخر لذ يجب التصدي لهذه الظاهرة المرضبة و العمل على تخفيفها

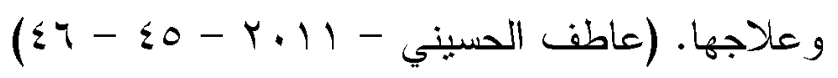


العلاج الإرشاد النفسي: - ويشمل الإرشاد العلاجي والإرشاد النفسي في حل

$$
\text { مشكلات الثخص (المرجع السابق - بونج) }
$$

العلاج البيئي: - أي تعديل العوامل البيئية ذات الأثر الملحوظ مثل تغير العمل

وتخفيف أعباء المريض وتخفيف الضغوط الييئية.

العلاج الطبي:- للأعر اض الجسيمة المصاحبة وطمأنه المريض أنه لا يوجد لديه مرض جسمي واستخدام المسكنات وأن العلاقة وثثقه بين القلق والتحضر فكلما ذادت حضارة المجتمع زاد التوثز والقلق النفسي أبي أن الحضارة و التقافة ثمثل عوامل مهمه في إنتاج القلق النفسي وتوضح بعض الدراسات الأجنيية على أهمية pererswn) الاسترخاء كعلاج وقائي للقلق المستقبل مثل: دراسة ربيسكاسن بون 1986) و على أهمية الاتصال الاجنماعي كتدعيم وثائي من الوقوع في براثن قلق

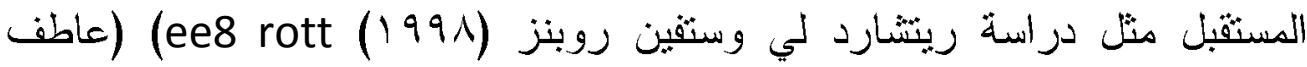

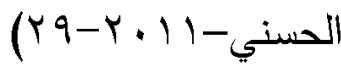

\section{العلاج السألوكي: -}

للاستخدام فنيات العلاج السلوكي ويمكن عرضها كما يلي: -

الطريقة الأولى: - إزالة الحساسية المسببة للمخاوف بطريقة منتظمة أي

خطوة خطوه وهي أولى أنواع العلاج السلوكي الهامة فهذه الطريقة ثشاعد في التخلص من المخاوف القلق فهي ثرنكز على المواجهة لتلك المخاوف فيخيل الثيء الذي يختُه قد حدث فعلا ويصاحبها استرخاء عميق للعضلات من خلال العلاج بالاسترخاء وتكون المواجهة أولا في الخيال حتى إذا تم إذالة تلك المخاوف تماماً من الخيال فإنه يمكن بعد ذلك المواجهة المخاوف على أرض الواقع إذا حدثت

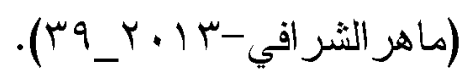

الطريقة الثانية الإغراق:- وهو أسلوب مواجهه فعليه لتلك المخاوف في الخيال دون الاستعانة بالاسترخاء العضلات فالمصاب بالقلق والخوف من المسنقبل 
بجد أن بتخيل أقصى مخاوفه أمامه، ويتخيل أن تلك المخاوف قد حدثت فعلاً ويتكيف على ذلك، ويكرر التخيل المبالغ فيه لمخاوفه فترة طويلة حتى يتكيف معها ويسنمر

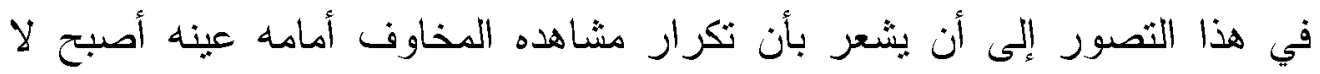
يثثرهو لا بقلقه لأنه إعتاد على تصوره وهكذا نجد أن ذلك النخص بهذا الإسلوب قد تعلم ذهنياً كيف يواجه أسوء ثقديرات الخوف والقلق، ويثعامل معها في خياله،

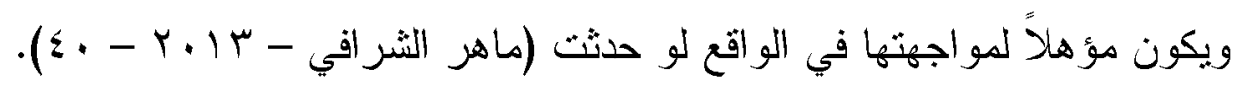

الطريقة الثالثة: - إعادة التتظيم المعرفة بهذه الطريقة العلمية تمت متابعتها وحققت نجاحاً كييرًا بعد أن لوحظ أن الذين بعانون من القلق والخوف من المستقبل يشغلون أنفسه دائما بالتفكير السلبي وهو ما يؤدى إلى حالة القلق والخوف. فإن هذه

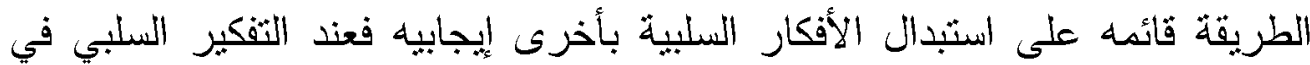
الأشياء التي ثثير القلق والمخاوف حيث يثم التفكير في الإيجابيات بدل السلبيات، و هذه الإعادة في نتظيم التفكير و استبدال النتائج الإيجابية المنوقعة لتحل محل النتائج السلبية وهذا التظظيم المعرفي للإنسان السوى الأى يثوقع النجاح كما يتوقع الفنّل

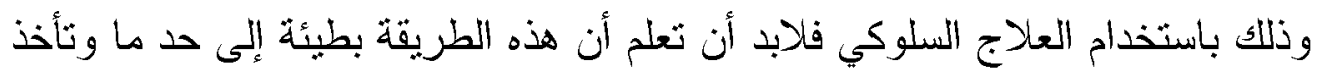
فترة زمنيه طويله إلى أن ينتهي الأنسان من التخلب على مخاوفه، ولعل أفضل هذه إنه الطرق السابقة والثي يستجيب إلبها الكثيرون طريقة التدرج البطيءالمتأني الثي التي يصاحبها الاسترخاء لان التّريب على الاسترخاء يساعد في زيادة اكتساب الأنسان

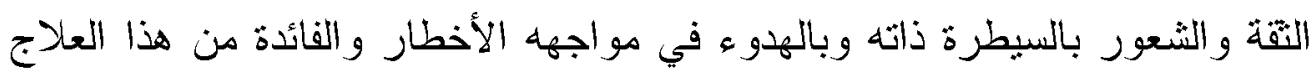

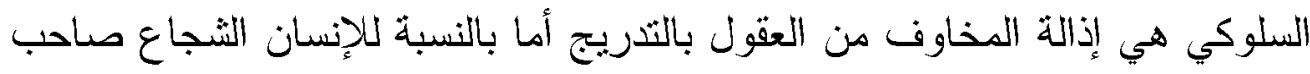

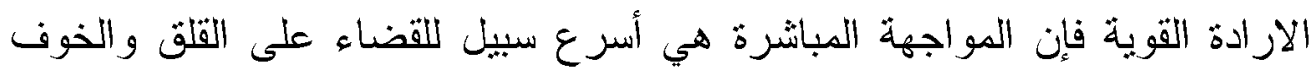

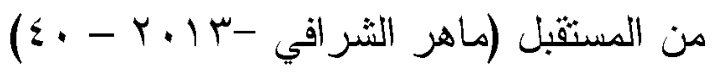

العلاج بالدين والبعد الروحي:- من العرض السابق لطرق العلاج عند علماء النفس نجد أنه يتعامل مع أعراض جسيمة الفسيولوجية - النفسية أو الاجنماعية وكثيراً ما نغفل العلاج بالبعد الديني والروحي في تعامل الفرد مع ربه وأثناء تربينتا 
لأو لادنا لا ننسى التنشئة الدبنه لبصل الانسان إلى حالة الرضا و الطمأنبية ونجعله

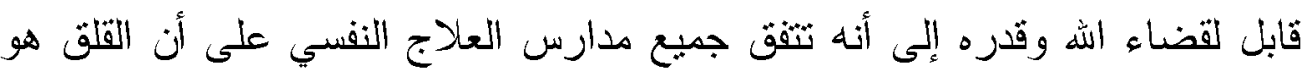
السبب الرئيسي في نشوء الاعراض النفسية ونتفق على أن هدف العلاج النفسي

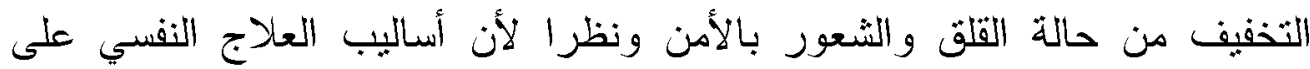
اختلاف انو اعها لم تتجح دائما في نحقيق الثفاء الثام من الامر اض النفسية فان إتباع منهج الهلوسنة رسوله يفي باحتياج النفس من الامن والطمأنينة وبكسبة مناعة ووقاية

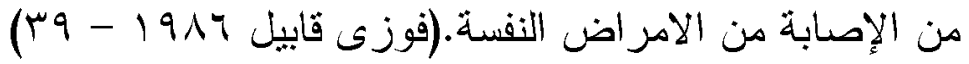

و المؤمن لا يشعر بالقلق الناشئ عن الإحساس اللشتعور بالأنب لأنه ثربى

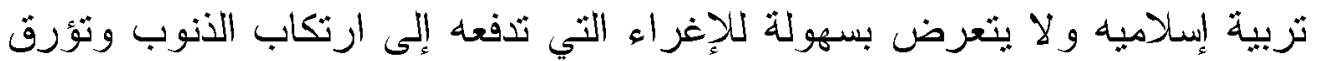
ضميز و عندما يخطئ ينذكر خطاه ويعثرف به ويستغفر الله وينوب عليه "قال تعالى" ومن يعمل سوء أو يظلم نفسه ثم يستغفز الله يجد اله غفور رحيما " (النساء • (1)

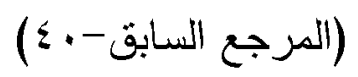
فاذا امتحن العبد فان صبر فان ذلك من عزم الأمور " وقال تعالى " واصبر

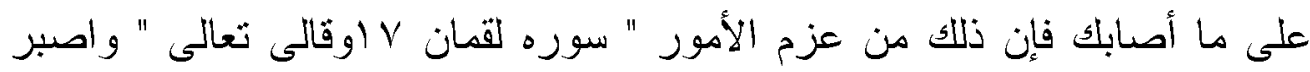

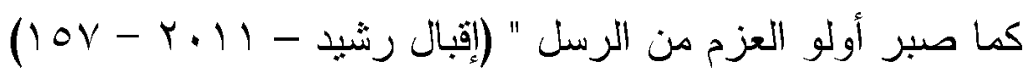

فان القلق ينشأ لدى الفرد نتيجة لمخالقته الثربعة الله وعدم اتباع نفسه لأهو ائها والجري وراء مكاسب الدنبا دون اعتبار للحباة الأخرة حيث إن اخطر الصراعات لاى الإنسان هو الصراع بين (الخير والثنر / الحلال و الحرام) بمعنى أنه ينشأ بين النفس اللوامة وبين النفس الأمارة بسوء وتثأثز بذلك النفس المطمئنة حيث إنني أعثقد أنه يظهر القلق والأكراض النفسية دن خلال صراع الدوافع مع بعض الغرائز وفيها يتصارع قوتان منضادتان فقد نكون هناك رغبة في عمل شيء مع تحريم أو منع

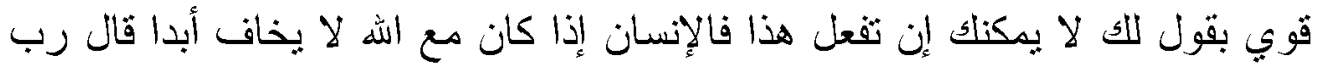
العز عز وجل (ولسوف بعطيك ربك فترضي) حيث أنه مرنبه الرضا نعمة لا لا لهابل يعطيها الله إلا من يستحقها ويرضي وان أبواب حب الله لعبده ورحمثه كثثر ولكن 
يجب علي الإنسانأن يصبر ويشكر اله في السراء والضراء كل هذا يؤدي إلى

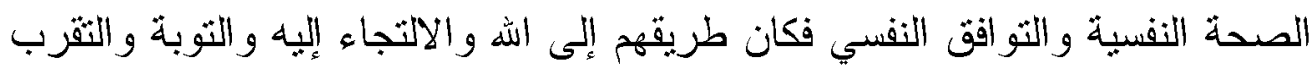
إلبه ولذلك أنه كلما كانت النتشئة الاجتماعية سليمة وثربية ثربوية جيدة للطفل و المر اهق قلت الاضطر ابات النفسية والعقلية والاجتماعية وبالتالي قلت ظهور القلق و علي العكس إذا كانت هناك سوء في التربية والتنشئة لدي الطقل والمر اهق إذا ذات الاضطر ابات النفسية والاجثماعية والعقلية فهو مرض العصر إلا وهو قلق المستقبل و علي المعالج النفسي أن يختار بين انسب الطرق التي تناسب مع كل حاله.

\section{قياس قلق المستقبل: -}

بعد الاطلاع علي المقياس العربية والأجنيبة التي نتاولت قلق المستقبل بلاحظ قله هذه المقاييس الني تتاولت مفهوم قلق المستقبل بصفه خاصدة وان كان في بعضها الأخر يمثل بعداً من أبعاد المقباس الأخرى أو ثتاولت ثلث المستقبل كعامل من عو امل مقياس ما وجد إن هذه المقياس قليله علي قدر علم الباحث المقياس قلق

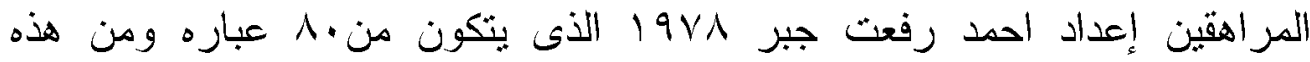
المقباس استيبان التوجيهات المستقبلة(1981) future orientation ويحثوي هذا الاستييان علي مقياس فرعي لقلق المستقبل وبثكون من أربعة عبار ات فقط وكذلك استفتاء لوليام وأخرون " سرو1 1 "Willa.al ويحثوى الاستفاء علي عامل يقيس قلق الأمهات المتعلق بالمستقبل علي أطفالهن ويتكون هذا العامل من (11) عبارة (احمد الح

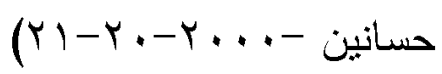

اختبار القلق الذكور المراهقين الذي يتكون من •ـ عباره (عصام فريد -

$(1919$

وقياس فقدان الأمل H.S HOPlessNessscale) H.إعداد لينيجس ileNiNGs تحديد اتجاه نحو المستقبل. 
مقياس منظور المستقبل إعداد السبد عبد الدايم عبد السلام (990 (1) ويتكون

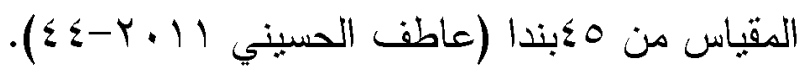

وتعتبر أول محاولة منظمة لأعداد مقباس خاص بقلق المستقبل ثلك التي قام بها محمد عبد التواب ب99 احيث ثام بأعداد مقياس لقق المسنثبل يتكون من (rr) عبارة نتدرج تحت ثمانية عوامل مختلفة، كما قام داليسكي (Zaleski 1997) بأعداد مقياس لقلق المستقبل وينكون هذا المقياس من (وجاعبارة) ثصف مثاعر الثخص ومخاوفه نحو المستقبل (احمد حسانين -...

وقام محمد معوض 1997 بمحاولة لأعداد مقياس القلق المستقبل ويتكون

المقياس من (Yr) عبارة. استبيان الثوجه نحو المستقبل إعداد (إبراهيم محمود إبر اهيم ب . . r) بهذف القياس الكمي لمستوي ثوجه النثباب الجامعي من الجنسين نحو المستفبل، وقد اسثثر الاسنييان على ،ـ عبارة في صورنه النهائية (عاطف

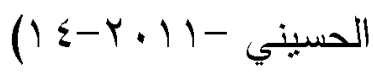

الملخص:قد نتاولت الباحنة في هذه الدراسة أهمية قلق المستقبل وتعريفه وأصل كلمة قلق المستقبل في اللغة وعند علماء المسلمين وعند علماء النفس كما ثتاولت أنواع قلق المستقبل والنظريات التي فسرت قلق المستقبل ومنها المدرسة السلوكية كما تتاولت سمات ذوي ثلق المستقبل وعلاجه وكيفية قياسه. 
احمد حسانين احمد محمد(. . . rم). "قلق المستقبل وقلق الامثحان وعلاقتها ببعض المتغيرات النفسبة لدي عبنة من طلابالصف الثاني الثانوي"

جامعة المنيا الآداب قسم علم نفس رسالة ماجستير في الآداب.

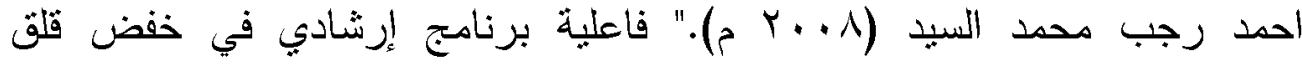
المسثقبل لدي اسر الأطفال المعاقين عقليا وأثزه على تعديل برسيل السلوك التكيفي لدي هؤلاء الأطفال"جامعة عين شمس كلبة البنات للادابو العلوم والتربية قسم ثربية الطفل رسالة دكتور اه في الثربية

فلسفة ثربية الطفل.

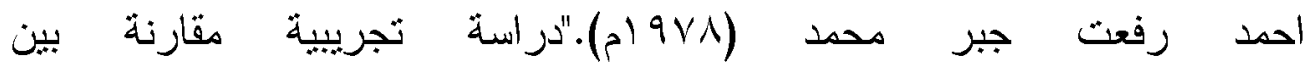
أثز إرشادالآباءو أثز إرشادو الأبناء على تحقيق القلق لدى المر اهقين " رسالة دكتور اهجامعة عين شمس كلية التربية قسم الصحة النفسية

استبرق غانم، رونق غانم، زينب حيدر (Y. V).'قلق المستثبل وعلاقته بمستوي الطموح لاي طلبة كلية الآدابجامعة القادسية ".

اسعد فاخر حبيب (ع ( ـrم)." ثلق المستقبل وعلاقته بمسنوي الطموح لدي طلبة الجامعة " جامعةالبصرة كليةالتربية للعلوم الإنسانية مجلة أبحاث

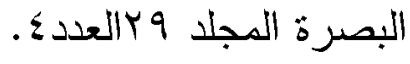

إقبال محمد رشبد صالح الحمداني(1 1 • Yم)."الاغنز اب و الثمرد قلق المستقبل" دار الصفا للطباعة و النشر، المملكةالأردنبة، مكتبةالإسكندرية 
امنه قاسم إسماعيل قاسم (11 + rم)."اضطر ابات الثخصبة العدو انبة السلبية و علاقتها بثوكبد الذات وتثديرها و التوقعات المستقبلية لدي طلاب الجامعة و الدر اسات العليا "رسالة دكثور اه في فلسفة الثزبية جامعة سو هاج كلية التربية قسم الصحة النفسية.

حسانين الكامل (ع/9 (م) "اختبار القلق الدراسي للمرحلة الثانوية " الناشر مكتبة النهضة بالقاهرة.

حنان محمد الجمال / نوال الثرقاوي بخبت(1 . . rم) "قلق البطالة وعلاقته بجوده الحباة وفاعلية الذاث طلاب السنة النهائية" بكلية التربية جامعة المنوفية مجلة البحوث النفسبةوالتربوية تصدرها كلية التربية جامعة المنوفية العدد الأول-السنة سبه

خلف احمد مبارك (ب99 (م)."حاله وسمة القلق وعلاقتهما بتأكيد الذات لدى طالبات مدارس الثمريض بصعيد مصر" مجلة نربوية، كليه التربية بسوهاج الجزء الأول، العدد الثامن.

خلف احمد مبارك (999 (م)."التو افق المهنيو علاقته بسمة القلق والاحتر القالنفسي لدى معلمي ومعلمات مدارس الثربية الخاصة " مجلة الثزبية جامعة

سوهاج كلية الثزبية مطبعة الجامعة بسوهاج العدد الرابع عثر • صالح بن محمد الصغير (1 +. (r)"التكيف الاجتماعي للطلاب الوافدين دراسة تحليلية مطبقة على طلاب جامعة الملك سعود بالرياض "مجلة

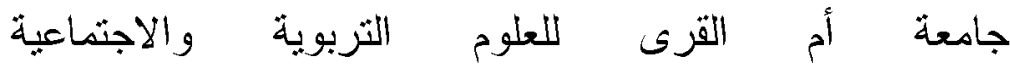
و الإنسانبةبمكة|المكرمة، المجلد الثالث عشر، العدد الأول. عاطف مسعد الحسيني(1 1 • بrم)."قلق المستقبل والعلاج بالمعنى "دار الفكر العربي

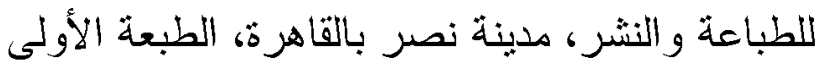




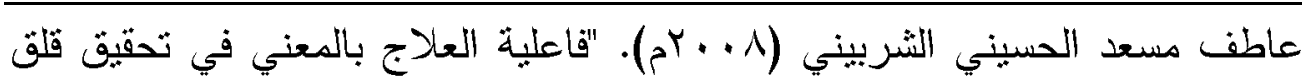
المستقبل لاي طلاب الجامعة “جامعة عين شمس، كلية التربية،

$$
\text { قسم الصحة النفسية، رسالة دكتور اه. }
$$

عصام فريد عبد العزيز محمد (بها9 (م)."المثغيرات النفسية المرثبطة بسلوك العدو انين المراهقين وأثر الإرشادالنفسيفي تعديله" رسالة دكتوراه جامعه أسبوط كلية التربية سوهاج علم النفس. علي حسين مظلوم (V) . . . م). "مستوي الطموح الأكاديمي وعلاقته بجواد الحياة الضاغطة لاي طلابالجامعة "مجلة جامعة بابل، للعلوم الإنسانية

$$
\text { المجلد 1^ا- العدد الأول. }
$$

عمر رمضان معوض احمد (س • ( م)." قلق المستقبل وعلقته بمستوي الطموح لدي طلبة الجامعة معهد الدارساتو البحوث التربوية جامعة القاهرة

$$
\text { مجلة العلوم الثربوية العدد الثاني. }
$$

فتحية فرج محمد عبيد (T (1 Yم). 'تتمبة مستوى الطموح لدى طالبات الجامعة لتحسين الثعور بالسعادةالنفسية "مجلة البحث العلمبفي التربية

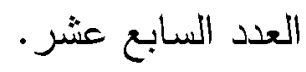

فوزي قابيل همام احمد(ب9 (م). دارسة تحليله لمستويات القلق في المراهقة و علاقتها بأساليب النتشئة الاجنماعيةجامعة أسيوط كلية التربية

قسم علم النفس رسالة دكتور اه تخصص صحة نفسية.

مأهر موسي مصطفي الثرافي (ب ا • rم). "الإنهاك النفسي وعلاقته بكل من قلق المستقبل ومستوي الطموح لدي العاملين في الأنفاق " رسالة ماجستير في الصحة النفسية قسم وعلم نفس جامعة الإسلامية بغزة. 
قلق المستقبل Future Anxiety

أل أسماء السيد قبيصى أبو زيد

المعجم الوجيز (1991 (م). مجمعاللغة العربية مطابع الأكيرية طبعة خاص بوزارة التزبية والتعليم تصدير بقلمابراهيم مدكور رئيس المجمع

$$
\text { مصطفي حجازي طبعة الأولى. }
$$

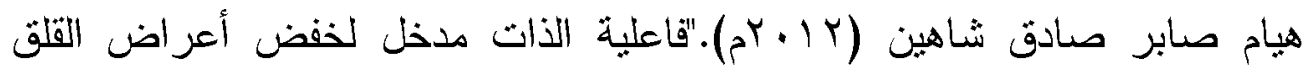
وتحسين التحصيل لاي عينثمن التلاميذ ذوب صعوبات التعلم

"مجلة جامعة دمشق المجلد ر ب، العدد الرابع. 